\title{
Translational Molecular Imaging of Prostate Cancer
}

\author{
Ana P. Kiess $\cdot$ Steve Y. Cho $\cdot$ Martin G. Pomper
}

Published online: 17 July 2013

(C) Springer Science+Business Media New York 2013

\begin{abstract}
Prostate cancer is a heterogeneous disease, and its management is now evolving to become more personalized and to incorporate new targeted therapy. With these new changes comes a demand for molecular imaging techniques that not only detect disease but also assess biology and treatment response. This review article summarizes the current status of molecular imaging in prostate cancer (e.g. ${ }^{99 \mathrm{~m}} \mathrm{Tc}$ bone scintigraphy and ${ }^{18} \mathrm{~F}$-fluorodeoxyglucose positron-emission tomography), with emphasis on emerging clinical and preclinical imaging agents, and their mechanism and clinical application. Emerging agents at different stages of clinical use include radiolabeled analogs of lipid, amino acid, and nucleoside metabolites, and agents more specifically targeting prostate cancer biomarkers, including androgen receptor, prostate-specific membrane antigen, and others. We also emphasize new techniques and targeted contrast agents for magnetic resonance imaging and spectroscopy. For all of these imaging techniques, a growing and important unfulfilled need is for well-designed prospective clinical trials which establish clear indications with clinical benefit in prostate cancer.
\end{abstract}

\section{A. P. Kiess}

Department of Radiation Oncology and Molecular Radiation Sciences, Johns Hopkins University School of Medicine, 401 North Broadway, Suite 1440, Baltimore, MD 21231, USA

\section{S. Y. Cho · M. G. Pomper $(\bowtie)$}

Russell H. Morgan Department of Radiology and Radiological Science, Johns Hopkins University School of Medicine, 1550 Orleans Street, 492 CRB II, Baltimore, MD 21231, USA e-mail: mpomper@jhmi.edu
Keywords Molecular imaging - Prostate cancer . Positron-emission tomography - Magnetic resonance imaging · Single-photon-emission computed tomography · Prostate-specific membrane antigen · Androgen receptor

\section{Introduction}

Prostate cancer is the most common cancer in American men, with an estimated annual incidence of 241,740 and mortality of 28,170 in 2012 [1]. The range of the disease is extremely broad-from indolent asymptomatic disease to aggressive metastatic disease. For this reason, clinical management is individualized on the basis of risk factors including stage, serum prostate-specific antigen (PSA) level, and pathologic Gleason score, as outlined in the risk stratification scheme of the National Comprehensive Cancer Network [2, 3]. Local treatment options include radical prostatectomy, external beam radiation, and brachytherapy with radioactive seed implantation. However, recent results increasingly support management of very low risk disease with active surveillance, because these patients are often over-treated $[4,5]$.

For patients with intermediate to high-risk or metastatic disease, the basis of systemic treatment is androgendeprivation therapy. Until recently, there were no effective treatments for castrate-resistant prostate cancer (CRPC). In the past five years, however, several agents have resulted in significant survival benefit in CRPC and join docetaxel [6] as therapeutic options for this disease. These agents include the anti-microtubule agent cabazitaxel [7], the oral CYP17 inhibitor abiraterone (which reduces testosterone production) $[8,9]$, the androgen receptor antagonist enzalutamide [10], and the autologous cancer vaccine sipuleucel-T [11]. With these new agents, treatment of metastatic prostate cancer is changing rapidly. 
The trend toward more personalized care and the development of new combination therapy for prostate cancer has resulted in a demand for more specialized biomarkers and imaging techniques. Serum PSA testing remains the standard of care for detection and monitoring, but has been limited by a low specificity $(20-40 \%)$ that is only partially improved by use of adaptations such as PSA density, PSA velocity, and free PSA [12]. Likewise, imaging techniques such as computed tomography (CT) and ${ }^{99 \mathrm{~m}} \mathrm{Tc}$-based bone scintigraphy have been limited by low accuracy, low specificity, and inability to detect nodal disease for bone scintigraphy [13]. There are specific clinical needs for improved imaging sensitivity for detection of micrometastatic disease during initial workup and for discrimination of locoregional versus distant disease in the setting of PSA relapse. Improved intraprostatic imaging could also affect local treatment choices and/or treatment planning. However, beyond the need for improved detection of the disease, there is a challenge for molecular imaging to assess its biology (e.g. indolent vs. aggressive) and treatment response (e.g. to androgen-deprivation and new CRPC treatments). This review article will summarize the many existing and emerging molecular imaging techniques for prostate cancer, with particular emphasis on their potential for mechanism-based and personalized approaches to disease management.

\section{Imaging Prostate Cancer: Present}

Traditional prostate cancer anatomic imaging techniques include transrectal ultrasound (TRUS), CT, and magnetic resonance imaging (MRI) [14]. TRUS, by anatomical imaging of the prostate gland, has become essential for guidance for interventions such as prostate biopsies and radioactive seed placement but its use for detection of prostate cancer is limited [15]. CT is commonly used for initial staging of intermediate to high-risk disease, to evaluate pelvic lymphadenopathy and gross extraprostatic disease extension. However, its sensitivity for detection of nodal metastases is only approximately $35 \%$ [13]. T2weighted endorectal MRI has superior soft tissue resolution to $\mathrm{CT}$ for evaluating local tumor extent, especially with use of an endorectal coil. MRI has many potential applications in prostate cancer, including initial staging, biopsy guidance, surgical planning, radiation planning, and restaging after PSA relapse [16]. However, it has not yet become widely accepted, partly because of unclear indications and high inter-observer variability.

At large referral centers with expert radiologists, multiparametric MRI is increasingly being used with diffusionweighted imaging (DWI), MR spectroscopic imaging (MRSI), and/or dynamic contrast enhancement (DCE-MRI).
DWI depicts the functional environment of water in tissue and the cellular status of normal and pathologic tissue and is, therefore, an indicator for characterization and differentiation of benign versus malignant lesions [17]. MRSI can improve prostate cancer specificity and can be used to assess tumor aggressiveness by detecting metabolic profiles characteristic of disease. In particular, the ratio of choline plus creatine to citrate in prostate voxels has a positive predictive value (PPV) of $90 \%$ in combination with MRI [18]. On DCE-MRI, early enhancement and washout is observed for prostate tumors, and this technique can further improve specificity and tumor localization. Multiparametric MRI may be especially valuable for characterization of intraprostatic lesions for patients managed with active surveillance and for patients with PSA relapse after radiation $[19,20]$.

Prostate cancer most frequently metastasizes to the bone with predominantly osteoblastic (sclerotic) pathogenesis. Therefore, the mainstay of imaging for advanced prostate cancer is ${ }^{99 \mathrm{~m}} \mathrm{Tc}$-labeled biphosphonate (e.g. ${ }^{99 \mathrm{~m}} \mathrm{Tc}$-methylene diphosphonate (MDP)) bone scintigraphy, which is based on the incorporation of the biphosphonate analog into hydroxyapatite crystals and collagen matrix. This molecular imaging technique is used for initial staging of intermediate to high-risk disease and for restaging after PSA relapse. It is highly sensitive and can be used to survey the entire skeleton with a simple planar scan [13]. However, it has limited specificity and is not sensitive enough to detect micrometastases. Single-photon-emission-tomography (SPECT) and SPECT/CT have been shown to improve the sensitivity and reduce the number of equivocal reports for detection of bone metastases in prostate cancer [21, 22]. Quantitative analysis using the bone scan index (BSI) has recently been shown to be prognostic for survival, and the BSI is also under investigation for assessment of treatment response [23, 24].

Positron-emission-tomography (PET) images of bone metastases may be achieved with ${ }^{18} \mathrm{~F}$-sodium fluoride which is also incorporated into hydroxyapatite crystals in bone. It has recently been demonstrated that ${ }^{18} \mathrm{~F}-\mathrm{NaF}$ PET is more sensitive than ${ }^{99 \mathrm{~m}} \mathrm{Tc}$ bone scan or SPECT for prostate cancer bone metastases, and incorporation of bone findings from CT with PET/CT results in improved specificity [21]. In a limited study, whole-body DWI MRI was more specific but less sensitive than ${ }^{18} \mathrm{~F}-\mathrm{NaF}$ PET/CT [25]. Another advantage of ${ }^{18} \mathrm{~F}-\mathrm{NaF}$ PET is the shorter scan time compared with bone scans. ${ }^{18} \mathrm{~F}$ $\mathrm{NaF}$ was approved by the FDA in 1972 for use with planar gamma scanners but resolution was poor compared with ${ }^{99 \mathrm{~m}} \mathrm{Tc}$-MDP. However, recent positive PET results and widespread availability of PET have prompted the initiation of a large ongoing prospective study of ${ }^{18} \mathrm{~F}-\mathrm{NaF}$ by the National Oncology PET Registry (NOPR) through the Centers for Medicare and Medicaid Services (CMS) (http://www.cancer petregistry.org/). 
${ }^{18}$ F-FDG PET has been of limited use in prostate cancer because of relatively low uptake after biochemical recurrence or in castrate-dependent disease and the nonspecific uptake of ${ }^{18} \mathrm{~F}$-FDG in prostatitis or benign prostatic hypertrophy $(\mathrm{BPH})$ for primary disease. However, there is evidence that ${ }^{18}$ F-FDG PET may be useful for restaging after PSA relapse and for assessment of treatment response in CRPC [26-29]. In particular, ${ }^{18}$ F-FDG PET is most useful for evaluating lymph node and bone metastases in patients with PSA $>2.4 \mathrm{ng} / \mathrm{mL}$ and PSA velocity $>1.3 \mathrm{ng} /$ $\mathrm{mL} /$ year [28]. In a recent study by Meirelles et al. [30], ${ }^{18}$ F-FDG PET was more sensitive than ${ }^{99 \mathrm{~m}} \mathrm{Tc}$ bone scan for bone metastases as a result of CRPC.

Several molecular imaging agents have been developed to target the biomarker prostate-specific membrane antigen (PSMA), an integral membrane glycoprotein that is highly upregulated in prostate cancer. A mouse monoclonal antibody against PSMA, ${ }^{111}$ In-capromab pendetide (ProstaScint), was approved by the FDA in 1996 and initially showed potential for restaging after PSA relapse. However, this agent repeatedly failed in the clinic, probably because of poor pharmacokinetics and failure to reach its target epitope on the intracellular portion of PSMA [31-33]. Other emerging techniques based on PSMA are quite promising and will be discussed below.

\section{Imaging Prostate Cancer: Experimental and Near- Term Future}

An increasing number of molecular imaging agents for prostate cancer are currently being tested on humans, and we expect several of these will be widely applied clinically in the near future. In broad categories, these probes include: lipid components $\left({ }^{11} \mathrm{C} /{ }^{18} \mathrm{~F}\right.$-choline and ${ }^{11} \mathrm{C}$-acetate $)$, amino acids $\left({ }^{11} \mathrm{C}\right.$-methionine, ${ }^{18} \mathrm{~F}$-FACBC leucine analog, and ${ }^{18} \mathrm{~F}$-glutamine), nucleoside analogs $\left({ }^{18} \mathrm{~F}\right.$-FMAU thymidine analog), molecular targeting agents $\left({ }^{18} \mathrm{~F}\right.$-FDHT for androgen receptor; ${ }^{111}$ In-J591, ${ }^{18}$ F-DCFBC and others for PSMA), and macrophage targeting agents (lymphotropic nanoparticles for MRI). We will address each of these categories with special emphasis on mechanism and potential clinical application (summarized in Table 1). However, for all of these agents, the greatest need is for prospective, controlled clinical trials to establish clear indications for use in prostate cancer.

\section{Lipid Metabolism Agents}

The development of ${ }^{18} \mathrm{~F}$-choline has recently been expertly reviewed by Bauman et al. [34] and will therefore only be summarized here. Briefly, prostate cancer cells have been shown to have increased fatty acid metabolism with up-regulation and increased activity of lipogenic enzymes [35].
${ }^{11} \mathrm{C} /{ }^{18} \mathrm{~F}$-choline and ${ }^{11} \mathrm{C}$-acetate in prostate cancer have been associated with choline kinase [36, 37] and fatty acid synthase [38], respectively. The major advantage of ${ }^{18} \mathrm{~F}$-choline is its longer half-life compared with ${ }^{11} \mathrm{C}$-choline (110 vs. $\left.20 \mathrm{~min}\right)$. However, urinary excretion is higher for ${ }^{18} \mathrm{~F}$-choline and it is accumulated in the bladder. These agents are not ideal for initial staging, because of false positives in prostatitis and $\mathrm{BPH}$ and false negatives in small $(<5 \mathrm{~mm})$ or necrotic tumors [39•]. However, they have potential for restaging after PSA relapse, with high sensitivity for local recurrence, nodal metastases, and bone metastases [40-43]. A recent study of PSA relapse by Giovacchini et al. [44•] showed that ${ }^{11} \mathrm{C}$-choline uptake correlates with PSA velocity and doubling time. Furthermore, Souvatzoglou and Rigatti [45, 46] have demonstrated the potential application of ${ }^{11} \mathrm{C}$-choline for personalized image-guided salvage radiation or lymph node dissection. The utility of ${ }^{11} \mathrm{C}$-choline after PSA relapse was further emphasized by its recent FDA approval for this indication at the Mayo Clinic. Similar to ${ }^{11} \mathrm{C}$-choline, ${ }^{11} \mathrm{C}$-acetate may be best used for restaging, and studies have shown enhanced sensitivity compared with ${ }^{18}$ F-FDG $[47,48]$. Direct comparison of ${ }^{11} \mathrm{C}$-acetate and ${ }^{11} \mathrm{C}$-choline by Kotzerke et al. [49] revealed no clear clinical differences between these agents.

\section{Amino Acid Analogs}

The amino acids leucine, methionine, and glutamine are effectively taken up by many tumors because of increased amino acid transport and metabolism. The most promising of these agents for prostate cancer imaging has been anti-1amino-3- ${ }^{18} \mathrm{~F}$-fluorocyclobutane-1-carboxylic acid (anti- ${ }^{18} \mathrm{~F}$ FACBC), an L-leucine analog with excellent tumor uptake and little urinary excretion. This probe has shown early clinical success in imaging primary and recurrent disease in the prostate, pelvic lymph nodes and bone, with improved sensitivity compared with ${ }^{111}$ In-capromab pendetide (Fig. 1) [50-52]. Another amino acid, ${ }^{11} \mathrm{C}$-methionine, has recently shown potential for initial evaluation of low and high-grade primary prostate tumors and for guidance of prostate biopsies for patients with elevated PSA and multiple negative biopsies [53, 54]. Finally, glutamine metabolism is upregulated in many tumors, and ${ }^{18} \mathrm{~F}$-labeled glutamine analogs are now emerging for imaging prostate cancer [55].

Nucleoside Analogs

The thymidine analogs ${ }^{18} \mathrm{~F}-2^{\prime}$-fluoro-5-methyl-1-beta-Darabinofuranosyluracil (FMAU) and ${ }^{18} \mathrm{~F}-3^{\prime}$-fluoro- $3^{\prime}$ deoxythymidine (FLT) are biomarkers of cellular proliferation. ${ }^{18} \mathrm{~F}$-FMAU has been evaluated in a phase 0 study of several cancers, and uptake in primary prostate cancer and bone metastases was observed [56]. Furthermore, preclinical 
Table 1 Current molecular imaging agents in prostate cancer (in clinical use or trials)

\begin{tabular}{lllll}
\hline Agent & Technique & Half-life & Mechanism & Application \\
\hline${ }^{18} \mathrm{~F}-\mathrm{FDG}$ & PET & $110 \mathrm{~min}$ & Glucose analog & PSA relapse \\
${ }^{99 \mathrm{~m}} \mathrm{Tc}-\mathrm{MDP}$ & Planar/SPECT & $6 \mathrm{~h}$ & Bone targeting (hydroxyapatite) & Bone metastases \\
${ }^{18} \mathrm{~F}-\mathrm{NaF}$ & PET & $110 \mathrm{~min}$ & Bone targeting (hydroxyapatite) & Bone metastases \\
${ }^{111} \mathrm{In}$-capromab pendetide & SPECT & $67 \mathrm{~h}$ & PSMA binding (antibody) & PSA relapse \\
${ }^{11} \mathrm{C} /{ }^{18} \mathrm{~F}-$ choline & PET & $20 \mathrm{~min} / 110 \mathrm{~min}$ & Lipid metabolism agent & PSA relapse \\
${ }^{11} \mathrm{C}$-acetate & PET & $20 \mathrm{~min}$ & Lipid metabolism agent & PSA relapse \\
${ }^{18} \mathrm{~F}-\mathrm{FACBC}$ & PET & $110 \mathrm{~min}$ & L-Leucine amino acid analog & TBD \\
${ }^{11} \mathrm{C}-$ methionine & PET & $20 \mathrm{~min}$ & Amino acid & Initial staging \\
${ }^{18} \mathrm{~F}-\mathrm{FMAU}$ & PET & $110 \mathrm{~min}$ & Thymidine analog & TBD \\
${ }^{18} \mathrm{~F}-\mathrm{FDHT}$ & PET & $110 \mathrm{~min}$ & Androgen receptor binding (testosterone-based) & Treatment response \\
${ }^{111} \mathrm{In}$-J591 & SPECT & $67 \mathrm{~h}$ & PSMA binding (antibody) & TBD \\
${ }^{18} \mathrm{~F}-\mathrm{DCFBC}$ & PET & $110 \mathrm{~min}$ & PSMA binding (urea-based) & TBD \\
${ }^{68} \mathrm{Ga}$-PSMA & PET & $68 \mathrm{~min}$ & PSMA binding (urea-based) & TBD \\
Ferumoxtran & MRI & N/A & Macrophage targeting (nanoparticles) & Lymph node metastases \\
\hline
\end{tabular}

Fig. 1 Axial anti- ${ }^{18}$ F-FACBC PET (a) and PET/CT (b) images from a 67-year-old patient with PSA relapse show intense activity in the left external iliac nodes (black arrow). Axial

${ }^{111}$ In-capromab pendetide SPECT (c) and SPECT/CT (d) images from the same patient reveal no significant activity in this region (white arrow). Reproduced with permission from Schuster et al. [52]
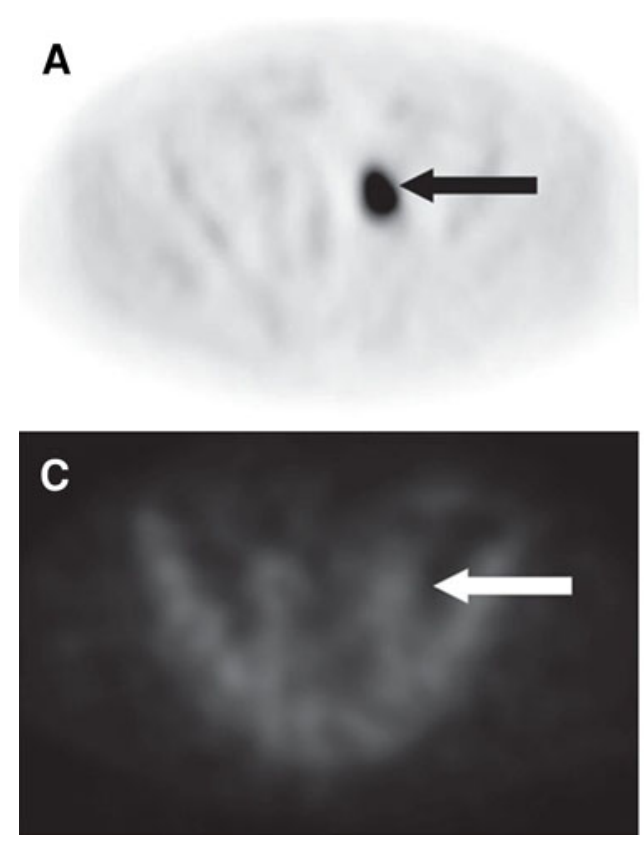
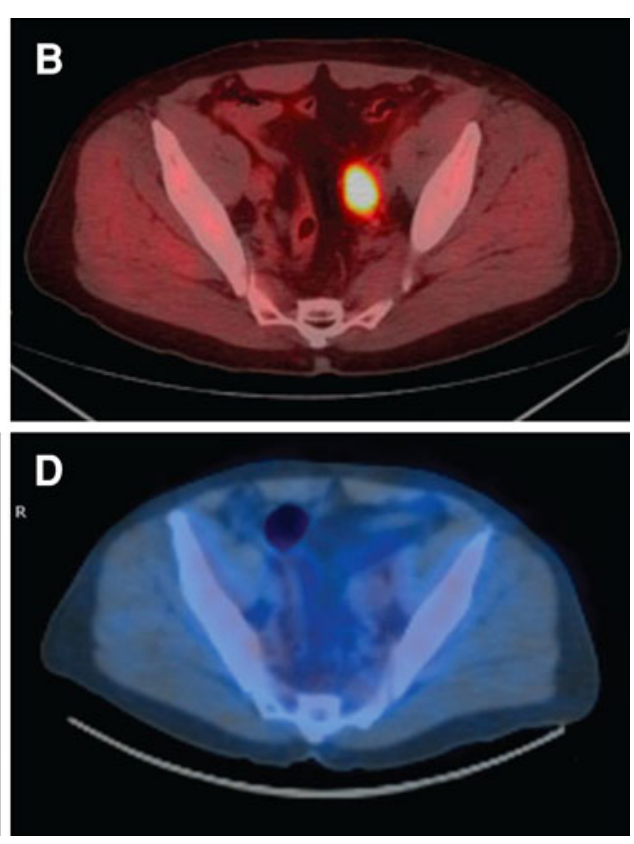

studies have demonstrated that ${ }^{18} \mathrm{~F}-\mathrm{FMAU}$ uptake is associated with androgen signaling, with increased uptake in castrated animals [57]. ${ }^{18} \mathrm{~F}-\mathrm{FLT}$ has potential in many cancers for evaluation of early treatment response; it is currently being tested in prostate cancer clinical trials after preclinical success in prostate models [58].

\section{Molecular Targeting Agents}

Direct imaging of androgen receptors in prostate cancer is now possible by use of ${ }^{18} \mathrm{~F}-16 \beta$-fluoro- $5 \alpha$-dihydrotestosterone (FDHT), and receptor binding specificity has been proved in humans by blocking with flutamide or testosterone $[59,60]$. Use of ${ }^{18}$ F-FDHT enables $78 \%$ tumor localization in patients with metastatic disease, but it is most unique in its successful application for PET pharmacodynamics in a phase I-II trial of the new androgen receptor antagonist enzalutamide for CRPC $[60,61 \bullet]$. In this study by Scher et al. [61••], PET imaging of 22 patients revealed reduced ${ }^{18}$ F-FDHT binding after four weeks of enzalutamide therapy (at all doses) compared with baseline (Fig. 2). This serves as proof of principle for application of molecular imaging agents for prostate cancer drug development and for assessment of individual treatment response [26, 59, 60]. 
Fig. $2{ }^{18}$ F-FDHT PET images at baseline (a) and after four weeks of treatment with enzalutamide (b). The sagittal and coronal images were taken $1 \mathrm{~h}$ after administration of ${ }^{18} \mathrm{~F}$ FDHT. After four weeks, they reveal reduction in ${ }^{18} \mathrm{~F}$-FDHT accumulation in tumors within the vertebrae, compared with the cardiac and aortic blood pool. Reproduced with permission from Scher et al. $[61 \bullet \bullet]$
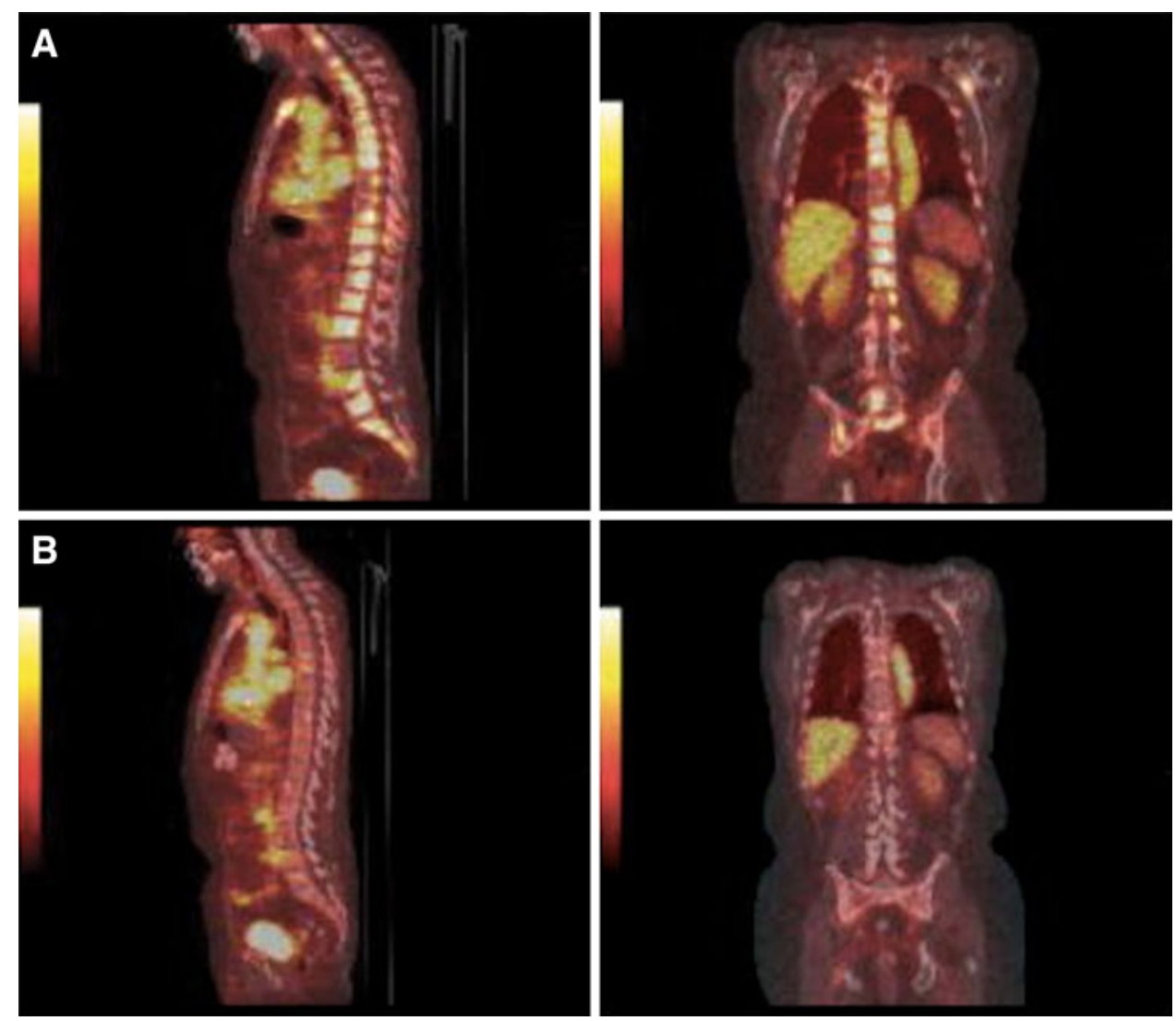

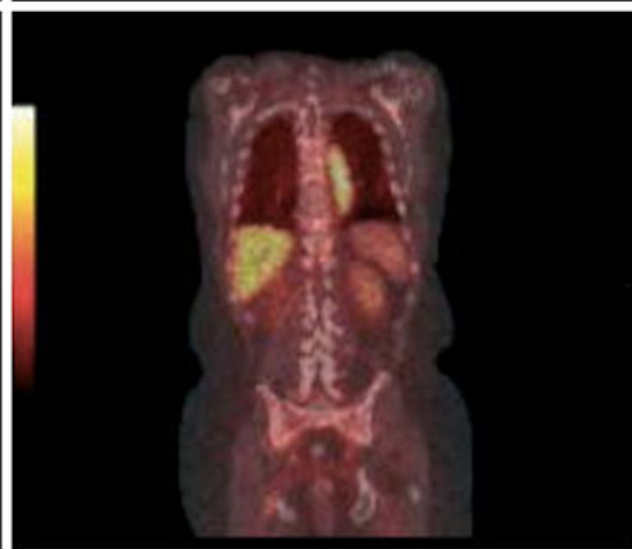

As noted above, PSMA is a well-characterized biomarker that has been recognized as a molecular imaging target in prostate cancer for many years. PSMA expression is associated with aggressive disease biology, and it is also upregulated by androgen deprivation [62-64]. Although clinical results with ${ }^{111}$ In-capromab pendetide have been disappointing, other promising PSMA probes are now entering clinical trials, including antibodies and small molecules. The monoclonal antibody J591, developed by Bander et al. [6567], targets the extracellular portion of PSMA and has been labeled with several PET and SPECT radionuclides. In earlyphase studies, ${ }^{111}$ In-J591 has enabled accurate detection of prostate cancer bone and soft tissue metastases; uptake by the tumor neovasculature of many solid tumors (in which PSMA is also expressed) has also been observed [65, 68]. Excellent tumor uptake and retention of the PET agent ${ }^{89} \mathrm{Zr}$-desferrioxamine B (DFO)-J591 has been observed in preclinical models, and it is now entering clinical trials [69•]. Figure 3 shows specific uptake of ${ }^{89} \mathrm{Zr}$-DFO-J591 in PSMA-positive LNCaP xenografts (tumor-to-muscle ratio of $26: 1$ at $144 \mathrm{~h}$ ) but not in PSMA-negative PC3 xenografts (tumor-to-muscle ratio of 5:1 at $144 \mathrm{~h}$ ) [69•]. Other antibody-based agents in preclinical development include ${ }^{64} \mathrm{Cu}-\mathrm{J} 591$, which has been used to demonstrate PSMA upregulation after androgen blockade, ${ }^{64} \mathrm{Cu}-3 / \mathrm{A} 12$, a monoclonal antibody to the extracellular portion of PSMA, and ${ }^{89} \mathrm{Zr}$-(DFO)-7E11, a monoclonal antibody to the intracellular portion of PSMA [70••, 71, 72].

To improve tumor uptake and clearance from non-target sites, our group and others have developed small molecules targeting PSMA [73, 74]. A low-molecular-weight, ureabased inhibitor of PSMA, ${ }^{18} \mathrm{~F}-\mathrm{N}$-[N-[(S)-1,3-dicarboxypropyl]carbamoyl]-4-fluorobenzyl-L-cysteine $\quad\left({ }^{18} \mathrm{~F}-\mathrm{DCFBC}\right)$ has been evaluated in a phase 0 trial for progressive metastatic prostate cancer. Bone and soft tissue metastases were successfully visualized by PET, as also were probable early bone lesions that were not seen on CT or ${ }^{99 \mathrm{~m}} \mathrm{Tc}-\mathrm{MDP}$ bone scan (Fig. 4) [75 ${ }^{\circ}$. A second-generation low-molecularweight ${ }^{18} \mathrm{~F}$-fluorine-labeled PSMA targeting agent, 2-(3-[1carboxy-5-[(6- $\left[{ }^{18} \mathrm{~F}\right]$ fluoropyridine-3-carbonyl)amino]pentyl]ureido)pentanedioic acid $\left({ }^{18} \mathrm{~F}\right.$-DCFPyL $)$, has also been developed, and preclinical studies have demonstrated high tumor-tobackground ratio $2 \mathrm{~h}$ post-injection of $39.4 \pm 5.4 \%$ injected dose per gram of tissue $(\% \mathrm{ID} / \mathrm{g})$ within PSMA-expressing tumor xenografts [76]. Rapid uptake by human bone and soft tissue metastases has also been shown for ${ }^{99 \mathrm{~m}} \mathrm{Tc}$-trofolastat, a PSMA-targeting SPECT agent developed by Molecular Insight Pharmaceuticals which is now in phase II trials [77]. We have also synthesized a ${ }^{99 \mathrm{~m}}$ Tc-radiolabeled PSMA agent for which, in preclinical studies, the tumor-to-background ratio 120 min post-injection was 44:1 [78]. Another urea-based inhibitor, Glu-NH-CO-NH-Lys-(Ahx)-[ $\left[{ }^{68} \mathrm{Ga}(\mathrm{HBED}-\mathrm{CC})\right]$ 

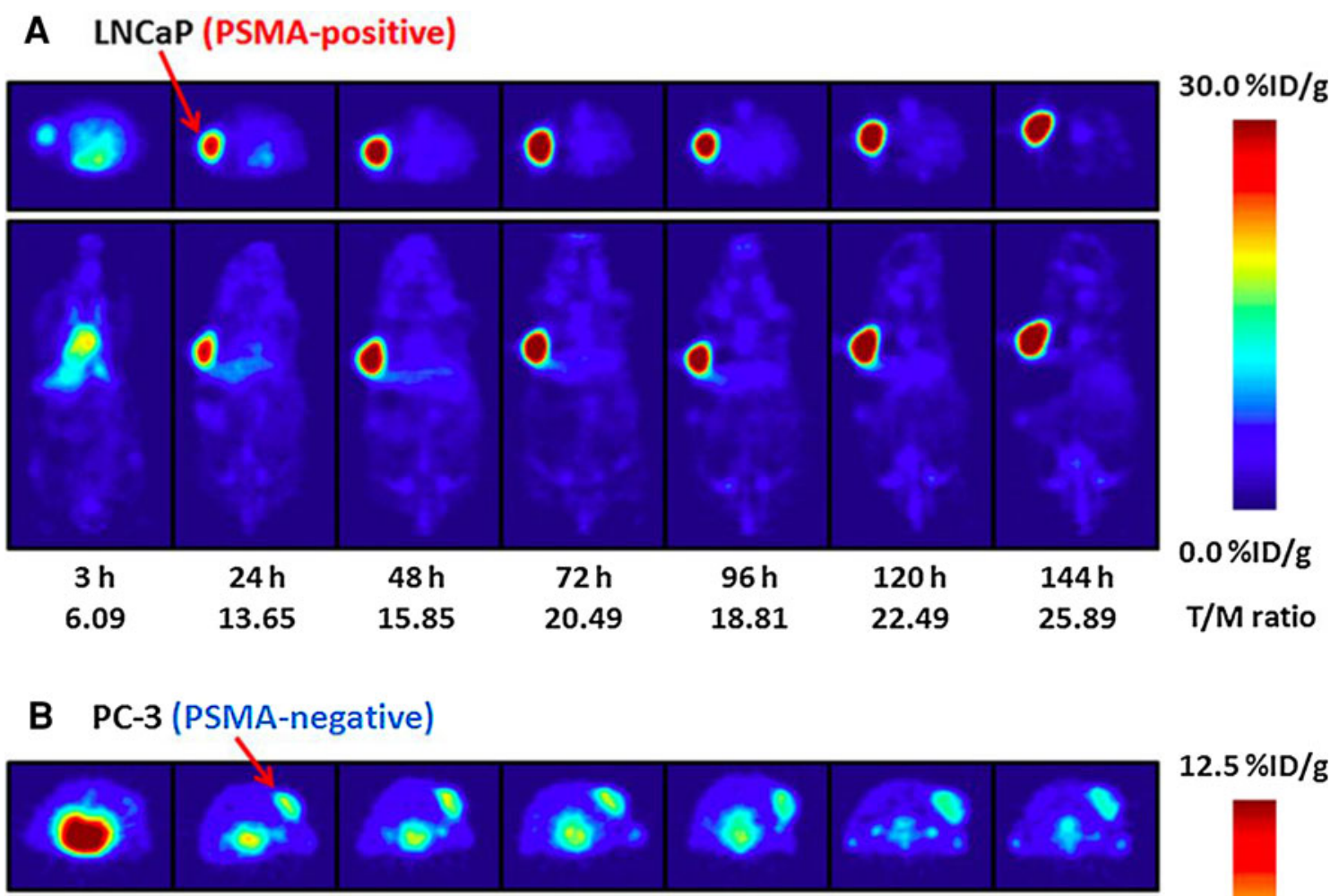

\section{$12.5 \% \mathrm{ID} / \mathrm{g}$}

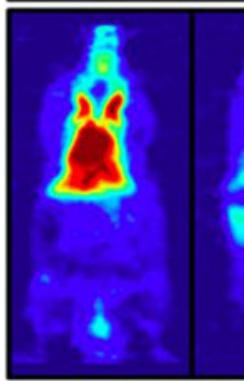

$3 \mathrm{~h}$

2.02

$24 \mathrm{~h}$

3.66

$48 \mathrm{~h}$

3.48

Fig. 3 Temporal PET images of ${ }^{89} \mathrm{Zr}$-DFO-J591 in mice bearing LNCaP xenografts (PSMA-positive, a) or PC-3 xenografts (PSMAnegative, b). Axial and coronal planar images at the center of the

$\left({ }^{68} \mathrm{Ga}-\mathrm{PSMA}\right)$, was recently tested on 37 prostate cancer patients; the median tumor-to-background ratio $3 \mathrm{~h}$ postinjection was 28:1 [79, 80]. Other urea-based agents with even higher binding affinity are in preclinical development [81].

\section{Macrophage Targeting Agents}

A class of functional MRI contrast agents has been developed to target macrophages within lymph nodes, a technique termed lymphotropic nanoparticle-enhanced MRI (LN-MRI) or MR lymphangiography. These agents are composed of inert ultra-small supraparamagnetic iron oxide (USPIO) particles (e.g. ferumoxtran) that are phagocytosed by macrophages and reduce T2-weighted signal in non-tumor areas. Sensitivity and specificity are

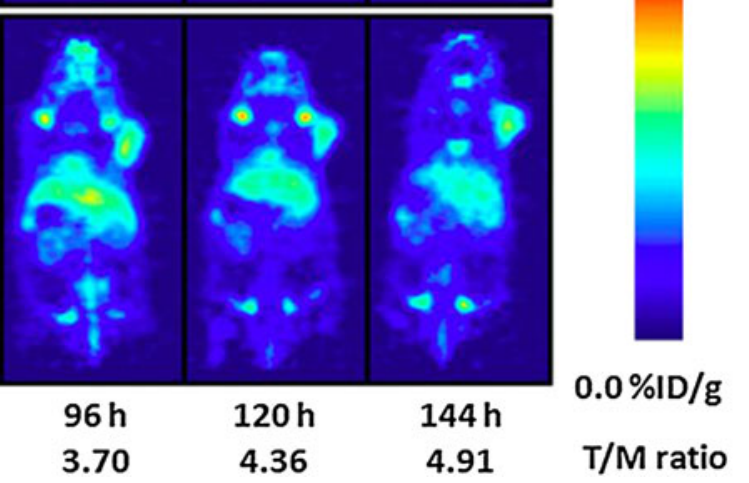

tumors show PSMA-specific uptake and retention of ${ }^{89} \mathrm{Zr}$-DFO-J591. Mean tumor-to-muscle ratios and upper thresholds of scale are shown. Reproduced with permission from Holland et al. [69•]

excellent for pelvic nodal metastases measuring at least $5 \mathrm{~mm}$ [82]. Indeed, a prospective multicenter study of 375 intermediate to high-risk patients confirmed that LN-MRI was significantly more sensitive than CT and had better negative predictive value for detection of nodal metastases [83]. This technique could be quite valuable for surgical or radiation treatment planning, because omission of pelvic nodal dissection and/or irradiation could significantly reduce toxicity.

\section{Imaging Prostate Cancer: New Compounds}

Many new compounds are under investigation for imaging prostate cancer and, as expected, most are highly specific 
Fig. $4{ }^{18}$ F-DCFBC PET images of a patient with progressive metastatic prostate cancer. An area of focal ${ }^{18} \mathrm{~F}-$ DCFBC uptake in the L4 vertebral body on PET and fused PET/CT (thick arrows, a) was not correlated with abnormality on CT (thin arrow, a) or bone scan (arrow, b). Reproduced with permission from Cho et al. [75•]
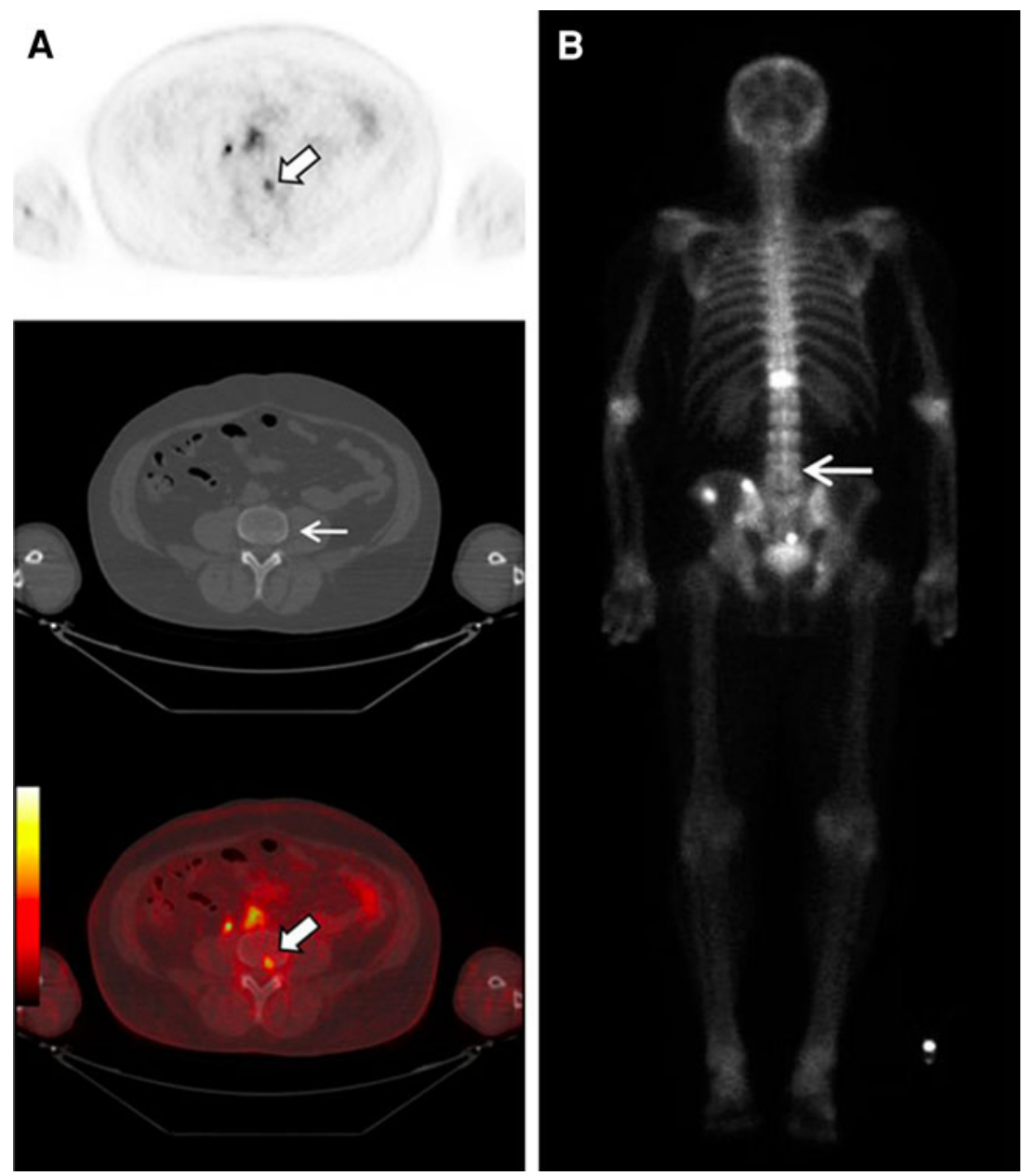

molecular targeting agents. This trend is consistent with the changing clinical and experimental approach to prostate cancer, and the move toward more mechanism-based treatment of this heterogeneous disease. In the next section, we emphasize recent preclinical studies, particularly focusing on those published in the past few years (summarized in Table 2).

\section{New Compounds for PET or SPECT}

A large variety of molecular targets are now being investigated for imaging prostate cancer, including tumor receptors and other specific biomarkers. A free PSA antibody (5A10) conjugated with ${ }^{89} \mathrm{Zr}$-(DFO) has been used in preclinical CRPC models to measure androgen receptordependent changes in tumor PSA expression [84]. This technique has the potential to measure treatment response to anti-androgens and other therapy. A group in Sweden has recently focused on the insulin-like growth factor-1 receptor (IGF-1R), which is involved in androgen independence and is an emerging drug target. IGF-1R-specific uptake in DU-145 xenografts, with a tumor-to-blood ratio of 3:1 after $8 \mathrm{~h}$, was observed for their affibody-based agent ${ }^{111}$ In-DOTA-Z IGF1R:4551 [85]. A series of ${ }^{99 m} \mathrm{Tc}$ labeled bombesin compounds have been developed to target the gastrin-releasing peptide receptor, which is overexpressed in many cancers; tumor-to-muscle ratios of up to 24:1 after $24 \mathrm{~h}$ have been observed for PC3 xenografts [86]. The vasoactive pituitary adenylate cyclase-activating peptide receptor-1 (VPAC1) is expressed in all prostate cancers; uptake of a VPAC1-targeting peptide probe, ${ }^{64} \mathrm{Cu}$ TP3939, by PC3 xenografts, with a tumor-to-muscle ratio of $6: 1$ after $24 \mathrm{~h}$, has been observed [87]. Hall et al. recently developed a monoclonal antibody to the epithelial cellular adhesion molecule EpCAM (expressed in many cancers) that is dual labeled with ${ }^{64} \mathrm{Cu}$-DOTA and IRDye $800 \mathrm{CW}$. In an orthotopic PC3 xenograft model they demonstrated $87 \%$ accuracy for identification of nodal metastases [88]. Counsell et al. [89, 90] have developed multiple radiolabeled versions of phospholipid ethers, which are abundant in a variety of tumors, and have shown tumor uptake of up to $18 \%$ of the injected dose per gram at day 5 for ${ }^{131} \mathrm{I}-\mathrm{NM} 404$ in PC3 xenografts. 
Table 2 Future molecular imaging agents in prostate cancer (in preclinical testing)

\begin{tabular}{|c|c|c|c|}
\hline Agent & Technique & Half-life & Mechanism/target \\
\hline${ }^{18} \mathrm{~F}-\mathrm{FLT}$ & PET & $110 \mathrm{~min}$ & Thymidine analog \\
\hline${ }^{89} \mathrm{Zr}-(\mathrm{DFO})-\mathrm{J} 591$ & PET & $78 \mathrm{~h}$ & PSMA (antibody) \\
\hline${ }^{64} \mathrm{Cu}-\mathrm{J} 591$ & PET & $13 \mathrm{~h}$ & PSMA (antibody) \\
\hline${ }^{99}{ }^{\mathrm{m}} \mathrm{Tc}$-trofolastat & SPECT & $6 \mathrm{~h}$ & PSMA (small molecule) \\
\hline${ }^{89} \mathrm{Zr}-(\mathrm{DFO})-5 \mathrm{~A} 10$ & PET & $78 \mathrm{~h}$ & Free PSA (antibody) \\
\hline${ }^{111}$ In-DOTA-Z IGF1R:4551 & SPECT & $67 \mathrm{~h}$ & Insulin-like growth factor receptor (affibody) \\
\hline${ }^{99 \mathrm{~m}} \mathrm{Tc}$-bombesin & SPECT & $6 \mathrm{~h}$ & Gastrin-releasing peptide receptor (small molecule) \\
\hline${ }^{64} \mathrm{Cu}-\mathrm{TP} 3939$ & PET & $13 \mathrm{~h}$ & $\begin{array}{l}\text { Vasoactive pituitary adenylate cyclase-activating } \\
\text { peptide receptor (small molecule) }\end{array}$ \\
\hline${ }^{64} \mathrm{Cu}$-DOTA-EpCAM mAb & PET & $13 \mathrm{~h}$ & Epithelial cellular adhesion molecule (antibody) \\
\hline${ }^{131} \mathrm{I}-\mathrm{NM} 404$ & SPECT & $8 \mathrm{~d}$ & Phospholipid ether \\
\hline M13-SBP-MNP & MRI & N/A & $\begin{array}{l}\text { Tumor matrix glycoproteins (bacteriophage with } \\
\text { nanoparticles and peptide) }\end{array}$ \\
\hline Gd-DOTA-CLT1 & MRI & N/A & Fibrin-fibronectin (small molecule) \\
\hline $\begin{array}{l}\text { Hyperpolarized } \\
{ }^{13} \mathrm{C} \text {-pyruvate/lactate }\end{array}$ & MRSI & N/A & Metabolite analog \\
\hline
\end{tabular}

\section{New Compounds for MRI or MRSI}

Several groups have recently targeted extracellular matrix proteins to improve MRI contrast enhancement in prostate cancer models. Ghosh et al. used a novel M13 bacteriophage as a carrier for multiple iron oxide nanoparticles and a peptide targeting the tumor matrix glycoprotein SPARC (M13-SBP-MNP). They showed excellent nanoparticle delivery and MRI contrast in prostate cancer xenograft models [91]. Another group used a small molecule approach, targeting fibrin-fibronectin complexes with the cyclic peptide CLT1 conjugated to Gd-DOTA. In an orthotopic PC3 model they showed high binding specificity and improved MRI contrast compared with non-targeted Gd-DOTA [92].

Hyperpolarized ${ }^{13} \mathrm{C}$ can be used as a contrast agent for MRI or MRSI, because it briefly retains its nuclear polarization after injection. Using a fast MRSI technique with ${ }^{13} \mathrm{C}$-labeled pyruvate and lactate in the transgenic adenocarcinoma of mouse prostate (TRAMP) model, Chen et al. $[93,94]$ effectively detected prostate tumors and correlated ${ }^{13} \mathrm{C}$-lactate uptake with tumor grade. In addition, Yaligar et al. [95] recently demonstrated that increased ${ }^{13} \mathrm{C}$-lactate correlated with tumor aggression in prostate cancer models. This technique thus has potential not only for detecting tumors but also for assessing their biology.

\section{Conclusion}

As the management of prostate cancer becomes more personalized and new treatments become available, there is increasing clinical demand for molecular imaging beyond ${ }^{99 \mathrm{~m}} \mathrm{Tc}$ bone scintigraphy and ${ }^{18} \mathrm{~F}$-FDG PET. In this review, we have emphasized the large number and great variety of emerging molecular imaging agents for prostate cancer. Many of these have been tested in early-phase clinical trials, and excellent potential for detection of primary and metastatic disease has been observed. We are particularly encouraged by several recent studies that demonstrate proof of principle for the use of molecular imaging to assess specific tumor biology or treatment response in prostate cancer. However, larger controlled trials will be necessary to establish clear clinical indications for these agents.

Acknowledgments Dr. Thomas M. Link reviewed this article.

Disclosure Ana P. Kiess, Steve Y. Cho, and Martin G. Pomper declare that they have no conflict of interest.

Compliance with Ethics Requirements This article does not contain any studies with human or animal subjects performed by any of the authors

\section{References}

Papers of particular interest, published recently, have been highlighted as:

- Of importance,

•• Of major importance

1. American Cancer Society. Cancer facts and figures 2012. Atlanta: American Cancer Society; 2012.

2. Thompson I, Thrasher JB, Aus G, et al. Guideline for the management of clinically localized prostate cancer: 2007 update. J Urol. 2007;177(6):2106-31.

3. National Comprehensive Cancer Network. Prostate cancer clinical practice guidelines (version 2.2013). http://www.nccn.org/ professionals/physician_gls/pdf/prostate.pdf. Accessed 28 May 2013. 
4. Klotz L, Zhang L, Lam A, et al. Clinical results of long-term follow-up of a large, active surveillance cohort with localized prostate cancer. J Clin Oncol. 2010;28(1):126-31.

5. Hayes JH, Ollendorf DA, Pearson SD, et al. Active surveillance compared with initial treatment for men with low-risk prostate cancer: a decision analysis. JAMA, J Am Med Assoc. 2010;304(21):2373-80.

6. Petrylak DP, Tangen CM, Hussain MH, et al. Docetaxel and estramustine compared with mitoxantrone and prednisone for advanced refractory prostate cancer. N Engl J Med. 2004;351 (15): 1513-20.

7. de Bono JS, Oudard S, Ozguroglu M, et al. Prednisone plus cabazitaxel or mitoxantrone for metastatic castration-resistant prostate cancer progressing after docetaxel treatment: a randomised open-label trial. Lancet. 2010;376(9747):1147-54.

8. de Bono JS, Logothetis CJ, Molina A, et al. Abiraterone and increased survival in metastatic prostate cancer. $\mathrm{N}$ Engl $\mathrm{J}$ Med. 2011;364(21):1995-2005.

9. Ryan CJ, Smith MR, de Bono JS, et al. Abiraterone in metastatic prostate cancer without previous chemotherapy. N Engl J Med. 2013;368(2):138-48.

10. Scher HI, Fizazi K, Saad F, et al. Increased survival with enzalutamide in prostate cancer after chemotherapy. N Engl J Med. 2012;367(13):1187-97.

11. Kantoff PW, Higano CS, Shore ND, et al. Sipuleucel-T immunotherapy for castration-resistant prostate cancer. N Engl J Med. 2010;363(5):411-22.

12. Prensner JR, Rubin MA, Wei JT, Chinnaiyan AM. Beyond PSA: the next generation of prostate cancer biomarkers. Sci Transl Med. 2012;4(127):127rv3.

13. Hricak H, Choyke PL, Eberhardt SC, et al. Imaging prostate cancer: a multidisciplinary perspective. Radiology. 2007;243(1): 28-53.

14. Cho SY, Pomper MG. Molecular imaging in prostate cancer. In: Pomper MG, Gelovani JG, editors. Molecular imaging in oncology. New York: Informa Healthcare; 2008.

15. Shinohara K, Wheeler TM, Scardino PT. The appearance of prostate cancer on transrectal ultrasonography: correlation of imaging and pathological examinations. J Urol. 1989;142(1): 76-82.

16. Sciarra A, Barentsz J, Bjartell A, et al. Advances in magnetic resonance imaging: how they are changing the management of prostate cancer. Eur Urol. 2011;59(6):962-77.

17. Bonekamp D, Jacobs MA, El-Khouli R, et al. Advancements in MR imaging of the prostate: from diagnosis to interventions. Radiographics. 2011;31(3):677-703.

18. Mueller-Lisse UG, Scherr MK. Proton MR spectroscopy of the prostate. Eur J Radiol. 2007;63(3):351-60.

19. Vargas HA, Akin O, Afag A, et al. Magnetic resonance imaging for predicting prostate biopsy findings in patients considered for active surveillance of clinically low risk prostate cancer. J Urol. 2012;188(5):1732-8.

20. Akin O, Gultekin DH, Vargas HA, et al. Incremental value of diffusion weighted and dynamic contrast enhanced MRI in the detection of locally recurrent prostate cancer after radiation treatment: preliminary results. Eur Radiol. 2011;21(9):1970-8.

21. Even-Sapir E, Metser U, Michani E, et al. The detection of bone metastases in patients with high-risk prostate cancer: ${ }^{99 \mathrm{~m}} \mathrm{Tc}-\mathrm{MDP}$ Planar bone scintigraphy, single- and multi-field-of-view SPECT, ${ }^{18}$ F-fluoride PET, and ${ }^{18}$ F-fluoride PET/CT. J Nucl Med. 2006;47(2):287-97.

22. Helyar V, Mohan HK, Barwick T, et al. The added value of multislice SPECT/CT in patients with equivocal bony metastasis from carcinoma of the prostate. Eur J Nucl Med Mol Imaging. 2010;37(4):706-13.
23. Dennis ER, Jia X, Mezheritskiy IS, et al. Bone scan index: a quantitative treatment response biomarker for castration-resistant metastatic prostate cancer. J Clin Oncol. 2012;30(5):519-24.

24. Ulmert D, Kaboteh R, Fox JJ, et al. A novel automated platform for quantifying the extent of skeletal tumour involvement in prostate cancer patients using the Bone Scan Index. Eur Urol. 2012;62(1):78-84.

25. Mosavi F, Johansson S, Sandberg DT, et al. Whole-body diffusion-weighted MRI compared with (18)F-NaF PET/CT for detection of bone metastases in patients with high-risk prostate carcinoma. AJR Am J Roentgenol. 2012;199(5):1114-20.

26. Fox JJ, Schoder H, Larson SM. Molecular imaging of prostate cancer. Curr Opin Urol. 2012;22(4):320-7.

27. Chang $\mathrm{CH}, \mathrm{Wu} \mathrm{HC}$, Tsai JJ, et al. Detecting metastatic pelvic lymph nodes by ${ }^{18} \mathrm{~F}$-2-deoxyglucose positron emission tomography in patients with prostate-specific antigen relapse after treatment for localized prostate cancer. Urol Int. 2003;70(4):311-5.

28. Schoder H, Herrmann K, Gonen M, et al. 2- $\left[{ }^{18} \mathrm{~F}\right]$ Fluoro-2deoxyglucose positron emission tomography for the detection of disease in patients with prostate-specific antigen relapse after radical prostatectomy. Clin Cancer Res. 2005;11(13):4761-9.

29. Morris MJ, Akhurst T, Larson SM, et al. Fluorodeoxyglucose positron emission tomography as an outcome measure for castrate metastatic prostate cancer treated with antimicrotubule chemotherapy. Clin Cancer Res. 2005;11(9):3210-6.

30. Meirelles GS, Schoder H, Ravizzini GC, et al. Prognostic value of baseline $\left[{ }^{18} \mathrm{~F}\right]$ fluorodeoxyglucose positron emission tomography and ${ }^{99 \mathrm{~m}} \mathrm{Tc}-\mathrm{MDP}$ bone scan in progressing metastatic prostate cancer. Clin Cancer Res. 2010;16(24):6093-9.

31. Deb N, Goris M, Trisler K, et al. Treatment of hormone-refractory prostate cancer with 90Y-CYT-356 monoclonal antibody. Clin Cancer Res. 1996;2(8):1289-97.

32. Thomas CT, Bradshaw PT, Pollock BH, et al. Indium-111-capromab pendetide radioimmunoscintigraphy and prognosis for durable biochemical response to salvage radiation therapy in men after failed prostatectomy. J Clin Oncol. 2003;21(9):1715-21.

33. Wilkinson S, Chodak G. The role of ${ }^{11}$ indium-capromab pendetide imaging for assessing biochemical failure after radical prostatectomy. J Urol. 2004;172(1):133-6.

34. Bauman G, Belhocine T, Kovacs M, et al. ${ }^{18} \mathrm{~F}$-fluorocholine for prostate cancer imaging: a systematic review of the literature. Prostate Cancer Prostatic Dis. 2012;15(1):45-55.

35. Zadra G, Photopoulos C, Loda M. The fat side of prostate cancer. Biochim Biophys Acta. 2013. doi:10.1016/j.bbalip.2013.03.010.

36. Contractor K, Challapalli A, Barwick T, et al. Use of $\left[{ }^{11} \mathrm{C}\right]$ choline PET-CT as a noninvasive method for detecting pelvic lymph node status from prostate cancer and relationship with choline kinase expression. Clin Cancer Res. 2011;17(24):7673-83.

37. Henriksen G, Herz M, Hauser A, et al. Synthesis and preclinical evaluation of the choline transport tracer deshydroxy- $\left[{ }^{18} \mathrm{~F}\right]$ fluorocholine ([ $\left.\left.{ }^{18} \mathrm{~F}\right] \mathrm{dOC}\right)$. Nucl Med Biol. 2004;31(7):851-8.

38. Vavere AL, Kridel SJ, Wheeler FB, Lewis JS. $1-{ }^{11} \mathrm{C}$-acetate as a PET radiopharmaceutical for imaging fatty acid synthase expression in prostate cancer. J Nucl Med. 2008;49(2):327-34.

39. - Souvatzoglou M, Weirich G, Schwarzenboeck S, et al. The sensitivity of $\left[{ }^{11} \mathrm{C}\right]$ choline PET/CT to localize prostate cancer depends on the tumor configuration. Clin Cancer Res. 2011;17(11):3751-59. This prospective study correlates histology of prostatectomy specimens with ${ }^{11} \mathrm{C}$-choline PET/CT images, showing the potential for false positives in prostatitis and $B P H$ and false negatives in small $(<5 \mathrm{~mm})$ or necrotic tumors.

40. Castellucci P, Fuccio C, Nanni C, et al. Influence of trigger PSA and PSA kinetics on ${ }^{11} \mathrm{C}$-choline PET/CT detection rate in patients with biochemical relapse after radical prostatectomy. J Nucl Med. 2009;50(9):1394-400. 
41. Picchio M, Castellucci P. Clinical indications of C-choline PET/ $\mathrm{CT}$ in prostate cancer patients with biochemical relapse. Theranostics. 2012;2(3):313-7.

42. Castellucci P, Fuccio C, Rubello D, et al. Is there a role for (11)Ccholine PET/CT in the early detection of metastatic disease in surgically treated prostate cancer patients with a mild PSA increase $<1.5 \mathrm{ng} / \mathrm{ml}$ ? Eur J Nucl Med Mol Imaging. 2011; 38(1):55-63.

43. Picchio M, Spinapolice EG, Fallanca F, et al. $\left[{ }^{11} \mathrm{C}\right]$ choline PET/ $\mathrm{CT}$ detection of bone metastases in patients with PSA progression after primary treatment for prostate cancer: comparison with bone scintigraphy. Eur J Nucl Med Mol Imaging. 2012;39(1):13-26.

44. - Giovacchini G, Picchio M, Parra RG, et al. Prostate-specific antigen velocity versus prostate-specific antigen doubling time for prediction of ${ }^{11} \mathrm{C}$-choline PET/CT in prostate cancer patients with biochemical failure after radical prostatectomy. Clin Nucl Med. 2012;37(4):325-31. In this retrospective study, high PSA velocity predicted for ${ }^{11} \mathrm{C}$-choline PET uptake in men with PSA relapse, showing the value of ${ }^{11} \mathrm{C}$-choline for detecting aggressive recurrent disease.

45. Souvatzoglou M, Krause BJ, Purschel A, et al. Influence of (11)C-choline PET/CT on the treatment planning for salvage radiation therapy in patients with biochemical recurrence of prostate cancer. Radiother Oncol. 2011;99(2):193-200.

46. Rigatti P, Suardi N, Briganti A, et al. Pelvic/retroperitoneal salvage lymph node dissection for patients treated with radical prostatectomy with biochemical recurrence and nodal recurrence detected by $\left[{ }^{11} \mathrm{C}\right]$ choline positron emission tomography/computed tomography. Eur Urol. 2011;60(5):935-43.

47. Oyama N, Miller TR, Dehdashti F, et al. ${ }^{11}$ C-acetate PET imaging of prostate cancer: detection of recurrent disease at PSA relapse. J Nucl Med. 2003;44(4):549-55.

48. Albrecht S, Buchegger F, Soloviev D, et al. (11)C-acetate PET in the early evaluation of prostate cancer recurrence. Eur $\mathrm{J}$ Nucl Med Mol Imaging. 2007;34(2):185-96.

49. Kotzerke J, Volkmer BG, Glatting G, et al. Intraindividual comparison of $\left[{ }^{11} \mathrm{C}\right]$ acetate and $\left[{ }^{11} \mathrm{C}\right]$ choline PET for detection of metastases of prostate cancer. Nucl Med. 2003;42(1):25-30.

50. Schuster DM, Taleghani PA, Nieh PT, et al. Characterization of primary prostate carcinoma by anti-1-amino-2-[(18)F]-fluorocyclobutane-1-carboxylic acid (anti-3-[(18)F] FACBC) uptake. Am J Nucl Med Mol Imaging. 2013;3(1):85-96.

51. Amzat R, Taleghani PA, Savir-Baruch B, et al. Unusual presentations of metastatic prostate carcinoma as detected by anti-3 F-18 FACBC PET/CT. Clin Nucl Med. 2011;36(9):800-2.

52. Schuster DM, Votaw JR, Nieh PT, et al. Initial experience with the radiotracer anti-1-amino-3- ${ }^{18} \mathrm{~F}$-fluorocyclobutane-1-carboxylic acid with PET/CT in prostate carcinoma. J Nucl Med. 2007; 48(1):56-63.

53. Toth G, Lengyel Z, Balkay L, et al. Detection of prostate cancer with ${ }^{11} \mathrm{C}$-methionine positron emission tomography. J Urol. 2005;173(1):66-9 (discussion 69).

54. Shiiba M, Ishihara K, Kimura G, et al. Evaluation of primary prostate cancer using ${ }^{11} \mathrm{C}$-methionine-PET/CT and ${ }^{18} \mathrm{~F}-\mathrm{FDG}-$ PET/CT. Ann Nucl Med. 2012;26(2):138-45.

55. Rajagopalan KN, DeBerardinis RJ. Role of glutamine in cancer: therapeutic and imaging implications. J Nucl Med. 2011;52(7): $1005-8$.

56. Sun H, Sloan A, Mangner TJ, et al. Imaging DNA synthesis with $\left[{ }^{18} \mathrm{~F}\right] \mathrm{FMAU}$ and positron emission tomography in patients with cancer. Eur J Nucl Med Mol Imaging. 2005;32(1):15-22.

57. Jadvar H, Yap LP, Park R, et al. $\left[{ }^{18} \mathrm{~F}\right]-2^{\prime}$-Fluoro-5-methyl-1-betaD-arabinofuranosyluracil $\left({ }^{18} \mathrm{~F}-\mathrm{FMAU}\right)$ in prostate cancer: initial preclinical observations. Mol Imaging. 2012;11(5):426-32.

58. Oyama N, Hasegawa $\mathrm{Y}$, Kiyono $\mathrm{Y}$, et al. Early response assessment in prostate carcinoma by (1)(8)F-fluorothymidine following anticancer therapy with docetaxel using preclinical tumour models. Eur J Nucl Med Mol Imaging. 2011;38(1):81-9.

59. Dehdashti F, Picus J, Michalski JM, et al. Positron tomographic assessment of androgen receptors in prostatic carcinoma. Eur $\mathbf{J}$ Nucl Med Mol Imaging. 2005;32(3):344-50.

60. Larson SM, Morris M, Gunther I, et al. Tumor localization of 16beta- ${ }^{18}$ F-fluoro-5alpha-dihydrotestosterone versus ${ }^{18} \mathrm{~F}-\mathrm{FDG}$ in patients with progressive, metastatic prostate cancer. J Nucl Med. 2004;45(3):366-73.

61. $\bullet$ Scher HI, Beer TM, Higano CS, et al. Antitumour activity of MDV3100 in castration-resistant prostate cancer: a phase 1-2 study. Lancet. 2010;375(9724):1437-46. This phase I-II trial of the androgen receptor antagonist enzalutamide was accompanied by ${ }^{18}$ F-FDHT PET imaging showing decreased binding after 4 weeks of enzalutamide therapy. This demonstrates the utility of molecular imaging for drug development and assessing individual treatment response.

62. Chang SS, Reuter VE, Heston WD, Gaudin PB. Comparison of anti-prostate-specific membrane antigen antibodies and other immunomarkers in metastatic prostate carcinoma. Urology. 2001;57(6):1179-83.

63. Perner S, Hofer MD, Kim R, et al. Prostate-specific membrane antigen expression as a predictor of prostate cancer progression. Hum Pathol. 2007;38(5):696-701.

64. Sweat SD, Pacelli A, Murphy GP, Bostwick DG. Prostate-specific membrane antigen expression is greatest in prostate adenocarcinoma and lymph node metastases. Urology. 1998;52(4):637-40.

65. Bander NH, Trabulsi EJ, Kostakoglu L, et al. Targeting metastatic prostate cancer with radiolabeled monoclonal antibody J591 to the extracellular domain of prostate specific membrane antigen. J Urol. 2003;170(5):1717-21.

66. Bander NH, Milowskiy MI, Nanus DM, et al. Phase I trial of ${ }^{177}$ lutetium-labeled J591, a monoclonal antibody to prostatespecific membrane antigen, in patients with androgen-independent prostate cancer. J Clin Oncol. 2005;23(21):4591-601.

67. Milowsky MI, Nanus DM, Kostakoglu L, et al. Phase I trial of yttrium-90-labeled anti-prostate-specific membrane antigen monoclonal antibody $\mathrm{J} 591$ for androgen-independent prostate cancer. J Clin Oncol. 2004;22(13):2522-31.

68. Milowsky MI, Nanus DM, Kostakoglu L, et al. Vascular targeted therapy with anti-prostate-specific membrane antigen monoclonal antibody J591 in advanced solid tumors. J Clin Oncol. 2007;25(5):540-7.

69. $\bullet$ Holland JP, Divilov V, Bander NH, et al. ${ }^{89} \mathrm{Zr}$-DFO-J591 for immunoPET of prostate-specific membrane antigen expression in vivo. J Nucl Med. 2010;51(8):1293-300. This preclinical study of the PSMA-targeting antibody PET agent ${ }^{89} \mathrm{Zr}$-DFO-J591 showed excellent tumor uptake and retention in LNCaP xenografts.

70. •• Evans MJ, Smith-Jones PM, Wongvipat J, et al. Noninvasive measurement of androgen receptor signaling with a positronemitting radiopharmaceutical that targets prostate-specific membrane antigen. Proc Natl Acad Sci USA. 2011;108(23):9578-82. This preclinical study used ${ }^{64} \mathrm{Cu}-J 591$ PET to quantitatively measure PSMA expression, showing that PSMA is upregulated by antiandrogen therapy. This provides an important proof of principle for using molecular imaging as a biomarker of receptor signaling.

71. Ruggiero A, Holland JP, Hudolin T, et al. Targeting the internal epitope of prostate-specific membrane antigen with ${ }^{89} \mathrm{Zr}-7 \mathrm{E} 11$ immuno-PET. J Nucl Med. 2011;52(10):1608-15.

72. Elsasser-Beile U, Reischl G, Wiehr S, et al. PET imaging of prostate cancer xenografts with a highly specific antibody against the prostate-specific membrane antigen. J Nucl Med. 2009;50(4):606-11.

73. Foss CA, Mease RC, Cho SY, et al. GCPII imaging and cancer. Curr Med Chem. 2011;19(9):1346-59. 
74. Mease RC, Foss CA, Pomper MG. PET imaging in prostate cancer: focus on prostate-specific membrane antigen. Curr Top Med Chem. 2013;13(8):951-62.

75. - Cho SY, Gage KL, Mease RC, et al. Biodistribution, Tumor Detection, and Radiation Dosimetry of ${ }^{18}$ F-DCFBC, a LowMolecular-Weight Inhibitor of Prostate-Specific Membrane Antigen, in Patients with Metastatic Prostate Cancer. J Nucl Med. 2012;53(12):1883-91. In this phase 0 clinical trial of the PSMAtargeting small molecule PET agent ${ }^{18} \mathrm{~F}$-DCFBC, bone and soft tissue metastases were successfully visualized in men with progressive disease, including early bone lesions that were not visible on CT or ${ }^{99 m}$ Tc bone scan.

76. Chen Y, Pullambhatla M, Foss CA, et al. 2-(3-\{1-Carboxy-5-[(6$\left[{ }^{18}\right.$ F $]$ fluoro-pyridine-3-carbonyl)-amino]-pentyl $\}$-ureido)-pentanedioic acid, $\left[{ }^{18} \mathrm{~F}\right] \mathrm{DCFPyL}$, a PSMA-based PET imaging agent for prostate cancer. Clin Cancer Res. 2011;17(24):7645-53.

77. Osborne JR, Hassan N, Vallabhajosula S, et al. Tc-99 m labeled small molecule inhibitors of prostate specific membrane antigen (PSMA): new molecular imaging probes to detect metastatic prostate adenocarcinoma. Chicago: American Society of Clinical Oncology; 2012.

78. Banerjee SR, Foss CA, Castanares M, et al. Synthesis and evaluation of technetium-99m- and rhenium-labeled inhibitors of the prostate-specific membrane antigen (PSMA). J Med Chem. 2008;51(15):4504-17.

79. Afshar-Oromieh A, Haberkorn U, Eder M, et al. [68 Ga]Galliumlabelled PSMA ligand as superior PET tracer for the diagnosis of prostate cancer: comparison with ${ }^{18} \mathrm{~F}-\mathrm{FECH}$. Eur J Nucl Med Mol Imaging. 2012;39(6): 1085-6.

80. Afshar-Oromieh A, Malcher A, Eder M, et al. PET imaging with a [(68)Ga]gallium-labelled PSMA ligand for the diagnosis of prostate cancer: biodistribution in humans and first evaluation of tumour lesions. Eur J Nucl Med Mol Imaging. 2012;40(4): 486-95.

81. Chen Y, Pullambhatla M, Banerjee SR, et al. Synthesis and biological evaluation of low molecular weight fluorescent imaging agents for the prostate-specific membrane antigen. Bioconjug Chem. 2012;23(12):2377-85.

82. Harisinghani MG, Barentsz J, Hahn PF, et al. Noninvasive detection of clinically occult lymph-node metastases in prostate cancer. N Engl J Med. 2003;348(25):2491-9.

83. Heesakkers RA, Hovels AM, Jager GJ, et al. MRI with a lymphnode-specific contrast agent as an alternative to CT scan and lymph-node dissection in patients with prostate cancer: a prospective multicohort study. Lancet Oncol. 2008;9(9):850-6.

84. Ulmert D, Evans MJ, Holland JP, et al. Imaging androgen receptor signaling with a radiotracer targeting free prostate-specific antigen. Cancer Discov. 2012;2(4):320-7.

85. Tolmachev V, Malmberg J, hofstrom C, et al. Imaging of insulin like growth factor type 1 receptor in prostate cancer xenografts using the affibody molecule ${ }^{111}$ In-DOTA-ZIGF1R:4551. J Nucl Med. 2012;53(1):90-7.

86. Yu Z, Carlucci G, Ananias HJ, et al. Evaluation of a technetium$99 \mathrm{~m}$ labeled bombesin homodimer for GRPR imaging in prostate cancer. Amino Acids. 2012;44(2):543-53.

87. Zhang K, Aruva MR, Shanthly N, et al. PET imaging of VPAC1 expression in experimental and spontaneous prostate cancer. J Nucl Med. 2008;49(1):112-21.

88. Hall MA, Pinkston KL, Wilganowski N, et al. Comparison of mAbs targeting epithelial cell adhesion molecule for the detection of prostate cancer lymph node metastases with multimodal contrast agents: quantitative small-animal PET/CT and NIRF. J Nucl Med. 2012;53(9):1427-37.

89. Counsell RE, Schwendner SW, Meyer KL, et al. Tumor visualization with a radioiodinated phospholipid ether. J Nucl Med. 1990;31(3):332-6.

90. Pinchuk AN, Rampy MA, Longino MA, et al. Synthesis and structure-activity relationship effects on the tumor avidity of radioiodinated phospholipid ether analogues. J Med Chem. 2006;49(7):2155-65.

91. Ghosh D, Lee Y, Thomas S, et al. M13-templated magnetic nanoparticles for targeted in vivo imaging of prostate cancer. Nat Nanotechnol. 2012;7(10):677-82.

92. Wu X, Burden-Gulley SM, Yu GP, et al. Synthesis and evaluation of a peptide targeted small molecular Gd-DOTA monoamide conjugate for MR molecular imaging of prostate cancer. Bioconjug Chem. 2012;23(8):1548-56.

93. Chen AP, Albers MJ, Cunningham $\mathrm{CH}$, et al. Hyperpolarized C-13 spectroscopic imaging of the TRAMP mouse at 3T-initial experience. Magn Reson Med. 2007;58(6):1099-106.

94. Albers MJ, Bok R, Chen AP, et al. Hyperpolarized ${ }^{13} \mathrm{C}$ lactate, pyruvate, and alanine: noninvasive biomarkers for prostate cancer detection and grading. Cancer Res. 2008;68(20):8607-15.

95. Yaligar J, Thakur SB, Bokacheva L, et al. Lactate MRSI and DCE MRI as surrogate markers of prostate tumor aggressiveness. NMR Biomed. 2012;25(1):113-22. 